\title{
Inflammatory Bowel Disease
}

The American Journal of Gastroenterology 104, 2241-2249 (September 2009) | doi:10.1038/ajg.2009.313

\section{Fatty Acids, IL6, and TNFa polymorphisms: an example of nutrigenetics in Crohn's disease}

Catarina Sousa Guerreiro, Paula Ferreira, Lourdes Tavares, Paula Moura Santos, Manuela Neves, Miguel Brito and Marília Cravo

\begin{abstract}
OBJECTIVES:

The aim of this work was to study the interaction between genetic polymorphisms (single-nucleotide polymorphisms, SNPs) of pro- and anti-inflammatory cytokines and fat intake on the risk of developing Crohn's disease (CD) or modifying disease activity.

METHODS:

Seven SNPs in interleukin 1 (IL1), tumor necrosis factor alpha (TNF $\alpha$ ), lymphotoxin alpha (LT $\alpha)$, and IL6 genes were analyzed in 116 controls and 99 patients with CD. The type of fat intake was evaluated, and the interaction between SNPs and dietary fat in modulating disease activity was analyzed.
\end{abstract}

RESULTS:

Individuals who were homozygous for the IL6-174G/C polymorphism had a six-fold higher risk for $C D$ (odds ratio $(O R)=6.1 ; 95 \%$ confidence interval $(95 \% \mathrm{Cl})=1.9-19.4)$, whereas the TT genotype on the TNF $\alpha-857 \mathrm{C} / \mathrm{T}$ polymorphism was associated with more active disease $(\mathrm{OR}=10.4 ; 95 \% \mathrm{Cl}=1.1-94.1)$. A high intake of total, saturated, and monounsaturated fats, as well as a higher ratio of $n-6 / n-3$ polyunsaturated fatty acid (PUFA), was associated with a more active phenotype $(P<0.05)$. Furthermore, there was an interaction between dietary fat intake and SNPs, with a high intake of saturated and monounsaturated fats being associated with active disease, mainly in patients carrying the variant alleles of the $857 \mathrm{TNF} \alpha$ polymorphism (OR=6.0, 95\% $\mathrm{Cl}=1.4-26.2$; $\mathrm{OR}=5.17 ; 95 \% \mathrm{Cl}=1.4-19.2$, respectively) and the $174 \mathrm{IL} 6$ polymorphism (OR=2.95; 95\% $\mathrm{Cl}=1.0-9.1 ; \mathrm{OR}=3.21 ; 95 \% \mathrm{Cl}=1.0-10.4$, respectively). Finally, low intake of $n-3$ PUFA and high n-6/n-3 PUFA ratio in patients with the TNF $\alpha 857$ polymorphism were associated with higher disease activity (OR=3.6; 95\% $\mathrm{Cl}=1.0-13.0 ; \mathrm{OR}=5.92 ; 95 \%$ $\mathrm{Cl}=1.3-26.5$, respectively).

CONCLUSIONS: 
These results show that different types of fat may interact with cytokine genotype, modulating disease activity. 